\title{
Preparation and Characterization of Thermoplastic Starch/Zein Blends
}

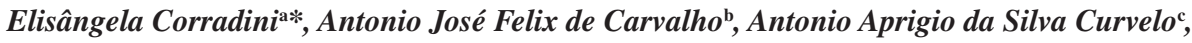 \\ José Augusto Marcondes Agnelli ${ }^{\mathrm{a}}$ Luiz Henrique Capparelli Mattoso ${ }^{\mathrm{d}}$ \\ ${ }^{a}$ Departamento de Engenharia de Materiais, Universidade Federal de São Carlos - UFSCar, \\ 13565-905 São Carlos, SP, Brazil \\ ${ }^{\mathrm{b}}$ Universidade Federal de São Carlos - UFSCar, Campus Sorocaba, \\ 18043-970 Sorocaba - SP, Brazil \\ 'Instituto de Química de São Carlos, USP, 13560-970 São Carlos - SP, Brazil \\ ${ }^{\mathrm{d}}$ Embrapa Instrumentação Agropecuária, 13560-970 São Carlos - SP, Brazil
}

Received: March 16, 2006; Revised: June 23, 2007

\begin{abstract}
Blends of starch and zein plasticized with glycerol were prepared by melting processing in an intensive batch mixer connected to a torque rheometer at $160{ }^{\circ} \mathrm{C}$. The resulting mixtures were compression molded and then characterized by scanning electron microscopy, differential scanning calorimetry, wide-angle $\mathrm{X}$ ray diffraction and water-absorption experiments. The blends were immiscible, showing two distinct phases of starch and zein. The water uptake at equilibrium and its diffusion coefficient were determined. The water uptake at equilibrium decreased with increasing zein content. The diffusion coefficient fell sharply on addition of $20 \%$ zein and remained constant as zein content was increased. No appreciable effect of zein on starch crystallization was observed by $\mathrm{X}$ ray diffraction. The use of zein in thermoplastic starch compositions causes a decrease in the water sensitivity of these materials and lower its melt viscosity during processing making zein a suitable and very promising component in TPS compositions.
\end{abstract}

Keywords: biodegradable polymers, thermoplastic starch, zein, polymer blends, thermal properties

\section{Introduction}

The utilization of natural renewable polymers, such as starch and proteins, in the production of biodegradable plastics is a promising topic for research and industrial development ${ }^{1,2}$.

Starch is one of the most studied natural polymers for plastic application, owing to its availability, biodegradability, and low $\operatorname{cost}^{3}$. Starch exists in a granular form in its natural state, but when subjected to shear forces at a temperature in the range $90-180{ }^{\circ} \mathrm{C}$, in the presence of a plasticizer such as glycerol, starch loses much of its original granular structure and is transformed into a molten plastic state named thermoplastic starch ${ }^{4}$. Unfortunately, thermoplastic starch has two main disadvantages in comparison with most plastics currently in use, namely that it absorbs moisture and exhibits poor mechanical properties. Several approaches have been taied to overcome these drawbacks, such as reinforcement with fibers ${ }^{5}$ and inorganic materials ${ }^{6}$ and with both degradable ${ }^{7}$ and non-degradable polymers ${ }^{8}$.

Zein is a protein present in corn in the seeds of maize in large amounts, which has a high content of hydrophobic amino acids (leucine, proline and alanine) ${ }^{9}$.

The combination of thermoplastic starch and plasticized zein might have great potential in the field of biodegradable plastics, since both can be processed in the presence of plasticizers, similarly to most conventional synthetic thermoplastic polymers. Additionally, the low solubility of zein in water could increase the hydrophobic character of the corresponding thermoplastic starch compositions.

In this paper, we describe the preparation of starch/zein blends plasticized with glycerol by melt processing in an intensive mixer. The materials were characterized by differential scanning calorimetry (DSC), X ray diffraction, water-uptake tests and scanning electron microscopy (SEM). The morphology of the blends was analyzed as a function of zein/starch ratio.

\section{Experimental Section}

Regular cornstarch containing 28\% amylose (Amisol 3408) was kindly supplied by Corn Products Brasil Ltd. Corn zein protein was purchased from Sigma Aldrich. Reagent grade glycerol was used as received.

\subsection{Material Processing}

Thermoplastic starch blends with zein were prepared with starch/ zein w. $w^{-1}$ ratios of $100 / 0,80 / 20,50 / 50,20 / 80$ and $0 / 100$. The content of glycerol was $22 \%$ by weight of the total weight of polymers (starch and zein), on a dry basis.

Starch, zein and glycerol were weighed separately, pre-mixed in a beaker and the resulting mixtures then processed at $160{ }^{\circ} \mathrm{C}$ in a Haake Rheomix 600 batch mixer connected to a torque rheometer, with the rotors operating at $50 \mathrm{rpm}$. The mixing time used for all preparations was 6 minutes, since higher mixing times leads to starch degradation. The materials thus obtained were pressed for 5 minutes at $160^{\circ} \mathrm{C}$ with a force of $0.2 \mathrm{MPa}$, to produce $150 \times 120 \times 2.5 \mathrm{~mm}$ molded sheets. These sheets were conditioned for four weeks at $22 \pm 3{ }^{\circ} \mathrm{C}$ at a relative humidity $(\mathrm{RH})$ of $52 \pm 2 \%$, prior to characterization. Glycerol losses were negligible, since the processing temperature was kept under the glycerol boiling point and no exudation was observed during processing.

\section{2. $X$ ray Diffraction}

$\mathrm{X}$ ray measurements of the conditioned samples were carried out using a Rigaku $\mathrm{X}$ ray diffractometer with nickel-filtered $\mathrm{CuK}_{\alpha}$ rays $(\lambda=1.542 \AA)$. The rotating-anode generator was operated at $20 \mathrm{kV}$ and $100 \mathrm{~mA}$. The scanning rate of the diffraction angle $2 \theta\left(3-40^{\circ}\right)$ was $1 \% \mathrm{~min}$. The degree of crystallinity of the samples was determined by a method described in the scientific literature ${ }^{10}$. 


\subsection{Differential scanning calorimetry (DSC)}

DSC tests were performed with a Shimadzu TA-50WSI calorimeter calibrated with indium. The samples were cut from the plates in circular form, weighed accurately $(\sim 10 \mathrm{mg})$, after conditioning at $52 \pm 2 \% \mathrm{RH}$, and placed in sealed aluminum pans in order to avoid water losses during the scans. Scannings were performed from 25 to $200{ }^{\circ} \mathrm{C}$ at a heating rate of $10^{\circ} \mathrm{C} / \mathrm{min}$, in a nitrogen flow.

\subsection{Water uptake}

Circular samples (11 mm diameter and $2.5 \mathrm{~mm}$ thickness), previously dried overnight at $105{ }^{\circ} \mathrm{C}$, were weighed and conditioned in hermetic containers at $97 \pm 2 \% \mathrm{RH}$ and $25 \pm 2{ }^{\circ} \mathrm{C}$, in the presence of saturated $\mathrm{K}_{2} \mathrm{SO}_{4}$ solution, as specified in ASTM E $104^{11}$. The amount of water absorbed by the samples was determined by weighing them periodically until a constant weight was attained. The water uptake (W) of the samples was calculated as follows:

$$
\mathrm{W}(\%) \times \frac{\mathrm{M}_{\mathrm{t}} \times \mathrm{M}_{0}}{\mathrm{M}_{0}} \times 100
$$

where $M_{t}$ is the weight at time $t$ and $M_{o}$ is the dry weight before exposure to $97 \pm 2 \% \mathrm{RH}$.

\subsection{Scanning electron microscopy}

The specimens were fractured after immersion in liquid nitrogen and sputter-coated with $20 \mathrm{~nm}$ of gold in a Balzers model SCD 50 sputter-coater. SEM micrographs were obtained with a Model DSM Zeiss Digital Scanning Microscope, using 10 to $15 \mathrm{kV}$ secondary electrons.

\section{Results and Discussion}

\subsection{Material Preparation}

The torque required to process starch, zein and starch/zein blends plasticized with glycerol was recorded as a function of mixing time (Figure 1). Typically, the torque curves obtained during the plasticization of polymers rise to a maximum in the initial stages of processing and then decrease, reaching a plateau with an almost constant value of torque. However, after the plasticization is complete, the torque can decrease, indicating chain degradation, or it can increase, indicating cross-linking or loss of plasticizer ${ }^{12}$.

Figure 1a shows the curves obtained for mixtures of starch and zein processed with 22,30 and $40 \%$ of glycerol. For the mixture of starch with glycerol, the torque value increased immediately to a maximum and decreased to a stable value, due to its melting and plasticization. It was observed that raising the of glycerol content from 22 to 30 and to $40 \%$ caused a torque reduction from 26 to 11 and to $4 \mathrm{Nm}$, respectively, indicating that melting and plasticization of the starch was facilitated by the progressive increase of the glycerol content. For zein/glycerol mixtures, the torques were much lower $(\sim 0.3 \mathrm{Nm})$ than those measured for the corresponding starch/glycerol mixtures, and no variation of torque was observed with increasing glycerol content. It was observed also that no change in the torque curves, after plastification of the polymers. This is an indication that no loss of plasticizer, crosslinking our degradation occured during the processing of mixtures the starch/glycerol and zein/glycerol.

The torque observed for the starch/zein/glycerol blends (Figure 1b) was intermediate between those observed for each natural polymer and started to increase after a certain processing time. This behavior is not completely understood and will be the focus of future studies. Chedid et al. ${ }^{13}$ showed that starch viscosity was significantly affected by the presence of proteins (zein, gliadin and

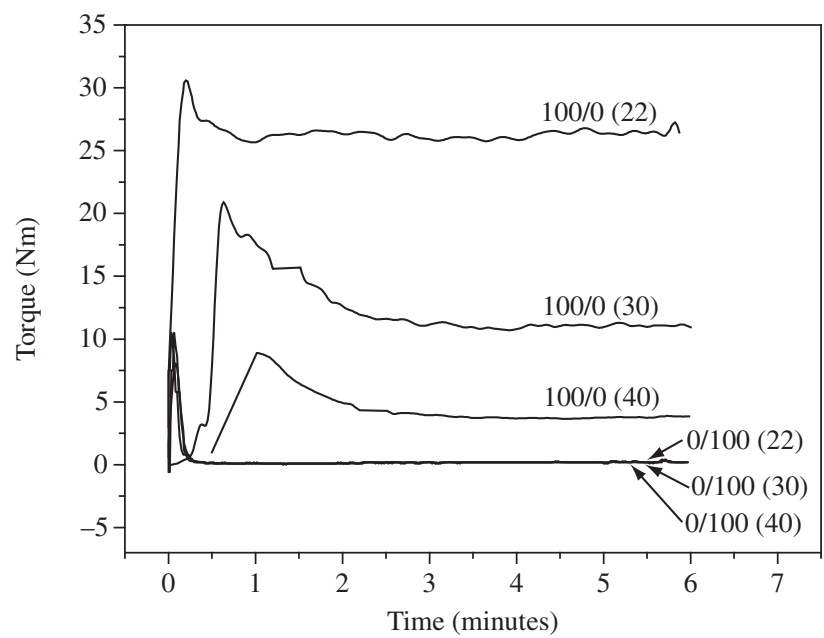

(a)

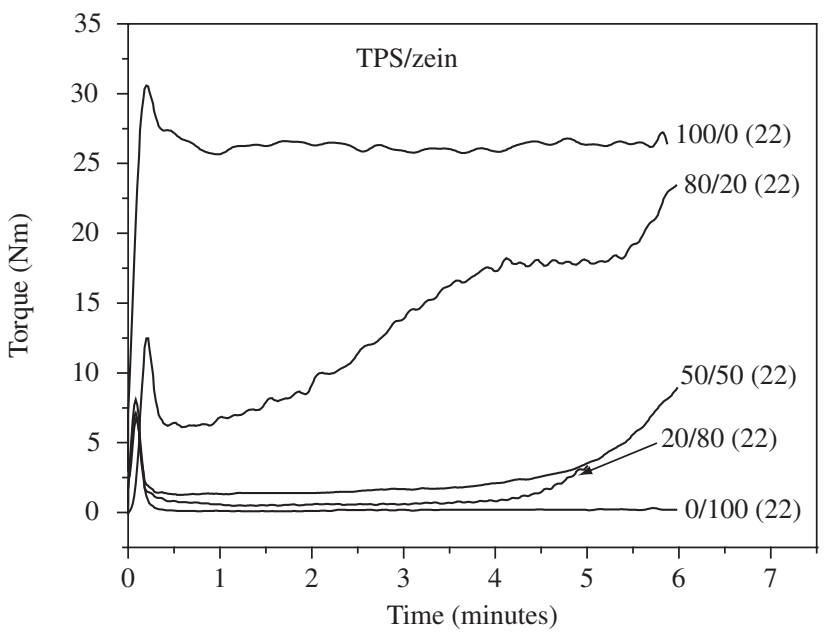

(b)

Figure 1. Torque as a function of mixing time. a) Starch and zein with 22, 30 and $40 \%$ of glycerol; and b) starch/zein blends plasticized with $22 \%$ glycerol. The numbers in brackets denotes the glycerol content.

glutelin), presumably because of interaction of hydrophilic portions of the protein with starch.

Two distinct torque behaviors were observed during the blending: a) low torque values, similar to those of the zein/glycerol mixture, were observed in the blends with 20 and $50 \%$ starch and b) high torque values, similar to those of the starch/glycerol mixture, were observed for the $80 \%$ starch blend. This behavior suggests that the blends were composed of two distinct phases, a TPS phase dispersed in a continuous zein phase or vice versa, depending on the blend composition. The torque behavior of the starch/zein blends showed that zein acted as a processing agent, which reduced the melt viscosity of the mixtures and facilated the plasticization of starch. Hence, lower temperatures and less mixing energy were required, reducing chain degradation during processing.

\subsection{X ray diffraction}

The $\mathrm{X}$ ray diffraction patterns of native starch granules, plasticized starch, plasticized zein, and their blends are presented in Figure 2. As a completely amorphous material, plasticized zein displayed no peaks on its diffractogram. Native starch (Figure 2a) showed an X ray 
scattering pattern with strong reflections at $2 \theta \sim 15^{\circ}$ and $23^{\circ}$ and an unresolved doublet at a $2 \theta$ of $17^{\circ}$ and $18^{\circ}$, which is a typical A-type pattern ${ }^{14}$. Thermoplastic starch (TPS) displayed crystalline structures which differed from that of native starch.

Thermoplastic starch is almost completely amorphous on extrusion, but if aged above its glass transition temperature, it crystallizes into the B-type structure, with a characteristic peak at $16.8^{\circ}(2 \theta)^{15}$. This structure is preferentially formed by crystallization of the short outer chains of amylopectin. It is also possible to identify another type of crystal structure formed by amylose-containing starches, viz. the $\mathrm{V}$-type, formed by the crystallization of amylose in single helices involving glycerol or lipids ${ }^{16}$, which occurs during extrusion or cooling. These complexes are responsible for the formation of insoluble materials when blends of starch with polymers like poly (vinyl alcohol) and copolymers of ethylene and vinyl alcohol are made ${ }^{17}$. The V-type crystalline structure can be divided into two subtypes, namely $\mathrm{V}_{\mathrm{a}}$ (anhydrous) with peaks at $13.2^{\circ}$ plus $20.6^{\circ}$ and $\mathrm{V}_{\mathrm{h}}$ (hydrated) with peaks at 12.6 and $19.4^{\circ}$.

Figure $2 \mathrm{~b}$ shows the main B and V-type characteristic peaks for thermoplastic starch and for starch/zein blends. The investigation of V-type structures is of great interest because the formation of a

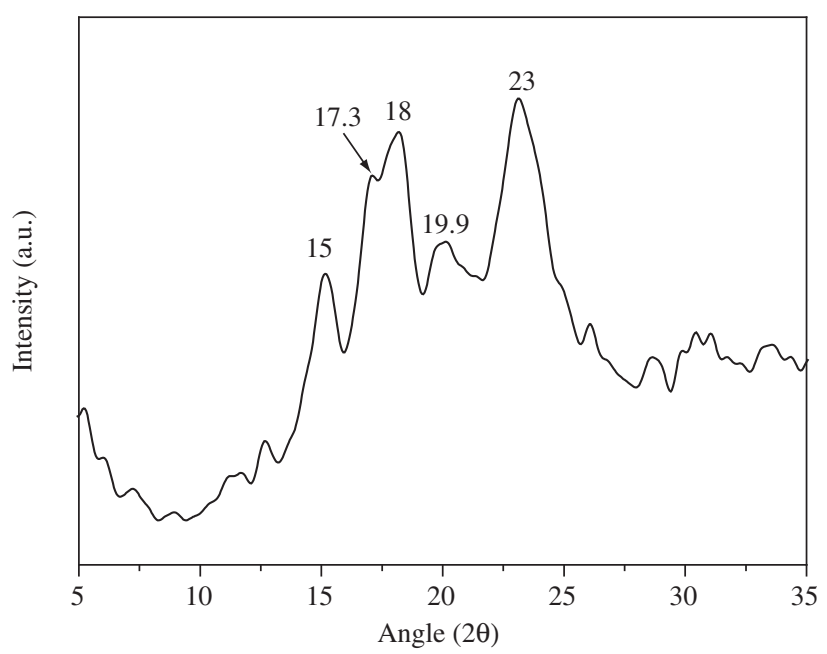

(a)

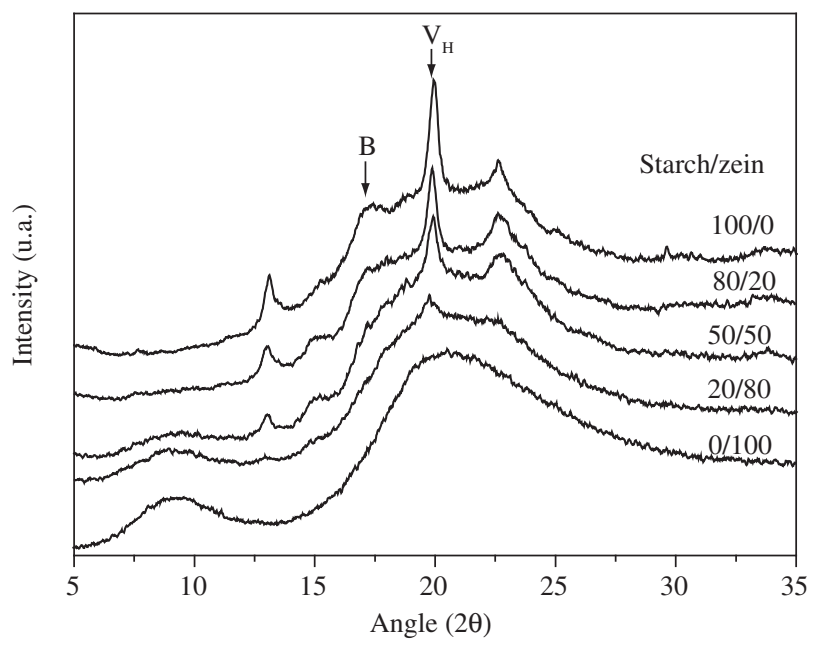

(b)

Figure 2. X ray diffraction patterns of (a) native starch and (b) thermoplastic starch, zein, and their blends plasticized with $22 \%$ glycerol. starch/zein V-complex could lead to a more hydrophobic material, which is highly desirable. Table 1 gives the crystallinity index data for the B-type and $\mathrm{V}_{\mathrm{h}}$-type crystalline structures, calculated as described by Hulleman et al. ${ }^{10}$. The data was normalized to the starch content. No appreciable modification was observed in the relative amounts of either the $\mathrm{V}_{\mathrm{h}}$ - or the B-type crystallinity, as zein content was increased. Moreover, these results showed no evidence of any starch/zein complex formation.

\subsection{Differential scanning calorimetry}

DSC measurements were performed from room temperature to $200{ }^{\circ} \mathrm{C}$ in order to detect the melting temperature of TPS, which has been described as being in the temperature range $110-150{ }^{\circ} \mathrm{C}^{17,18}$. The melting temperatures of the blends are given in Table 1 . The melting temperature of the TPS remained nearly constant with the addition of zein. This type of behavior indicates that the starch/zein blends are immiscible. The plasticized zein exhibited no melting features, because it was completely amorphous and the glass transition temperature was not determined as this transition was hard to discern in the DSC tracings.

\subsection{Water uptake}

The results of the water uptake experiments are shown in Figure 3. The rate of water absorption was almost linear until the equilibrium plateau was reached at times between 75 and 100 hours. The addition of zein decreased the water uptake at equilibrium. This is probably

Table 1. Melting temperature ( $\mathrm{T}_{\mathrm{m}}$ ) from DSC data, crystallinity index (B Type and $\mathrm{V}$ type) obtained from $\mathrm{X}$ ray diffractograms and equilibrium water content after conditioning at $52 \pm 2 \% \mathrm{RH}$, of starch/zein blends plasticized with $22 \%$ glycerol.

\begin{tabular}{|c|c|c|c|c|}
\hline \multirow{2}{*}{$\begin{array}{l}\text { Starch/zein } \\
\quad \text { ratio } \\
\left(\%, \mathrm{w}^{-1}\right)\end{array}$} & \multirow{2}{*}{$\begin{array}{l}\text { Water content } \\
\quad(\text { wt. }(\%))\end{array}$} & \multirow[t]{2}{*}{$\mathrm{T}_{\mathrm{m}}\left({ }^{\circ} \mathrm{C}\right)$} & \multicolumn{2}{|c|}{ Crystallinity Index } \\
\hline & & & $\begin{array}{l}\text { Type B } \\
\left(16.8^{\circ}\right)\end{array}$ & $\begin{array}{l}\text { Type V } \\
\left(19.4^{\circ}\right)\end{array}$ \\
\hline $100 / 0$ & $10.4 \pm 0.2$ & $160 \pm 3$ & $0.25 \pm 0.05$ & $0.43 \pm 0.05$ \\
\hline $80 / 20$ & $9.6 \pm 0.2$ & $157 \pm 3$ & $0.36 \pm 0.05$ & $0.47 \pm 0.05$ \\
\hline $50 / 50$ & $9.0 \pm 0.3$ & $157 \pm 3$ & $0.43 \pm 0.05$ & $0.52 \pm 0.05$ \\
\hline $20 / 80$ & $9.4 \pm 0.3$ & $157 \pm 3$ & - & $0.59 \pm 0.05$ \\
\hline $0 / 100$ & $8.5 \pm 0.2$ & - & - & - \\
\hline
\end{tabular}

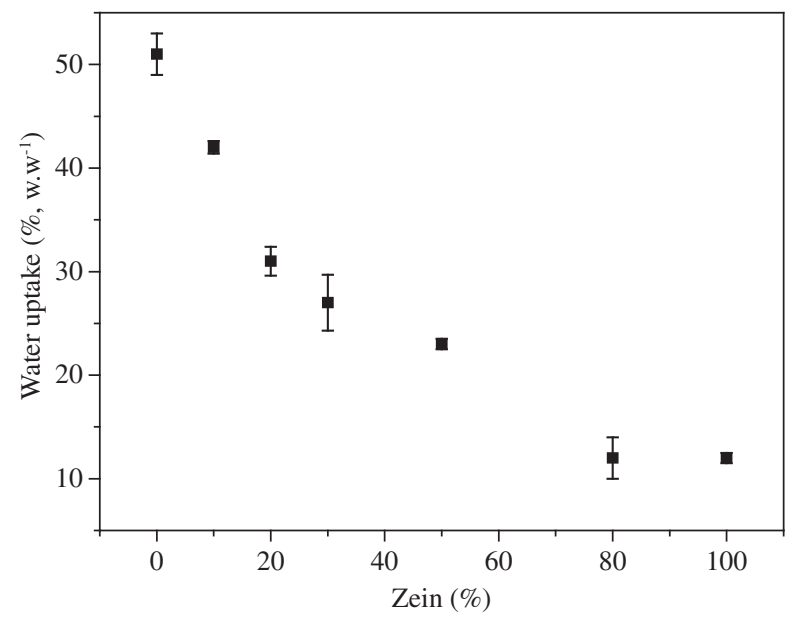

Figure 3. Water uptake at $97 \pm 2 \%$ RH vs. zein contents for starch/zein blends plasticized with $22 \%$ glycerol. 
due to the difference in hydrophilicity of zein and starch. Zein is composed of amino acids, many of which have apolar side groups, whereas starch has a very hydrophilic nature and interacts more strongly with water than zein does.

The diffusion coefficient of water was determined from the water uptake data, using Crank's equation for diffusion into a flat sheet $^{19}$ :

$$
\frac{M_{t}-M_{0}}{M_{\infty}}=\frac{2}{L}\left(\frac{D}{\pi}\right)^{1 / 2} t^{1 / 2}
$$

where $\mathrm{M}_{\infty}$ is the mass sorbed at equilibrium, $2 \mathrm{~L}$ the sample thickness and $\mathrm{D}$ the diffusion coefficient. This equation is valid for short-time measurements, where $\left(\mathrm{M}_{t}-\mathrm{M}_{0}\right) / \mathrm{M}_{\infty} \leq 0.5$. $\mathrm{D}$ was therefore estimated from a plot of $\left(\mathrm{M}_{t}-\mathrm{M}_{0}\right) / \mathrm{M}_{\infty}$ as a function of $\left(t / L^{2}\right)^{1 / 2}$.

The diffusion coefficient values were plotted against zein content (Figure 4) and D was found to decrease sharply upon addition of $20 \%$ zein and to remain practically constant for all further additions, including pure plasticized zein. These results indicated that water diffusion in these blends was regulated by the component in which water progressed more slowly, viz. zein, which therefore acted as a barrier. It is possible that the interface between phase also played an important role in the diffusion of water through the starch/zein blends.

\subsection{Scanning electron microscopy}

Scanning electron micrographs of fractured surfaces of starch/zein blends are shown in Figure 5. The morphology of the starch/zein blends changes with the variation in blend composition. The blend with $20 \%$ zein (Figure 5a) shows a flat surface with some domains, which already appear to indicate phase separation. The distinct phases are easily observed in the blends with 50 and $80 \%$ zein (Figures 5 b e 5c). The morphology of the blends also shows interfacial voids, indicating poor adhesion between starch and zein phases.

\section{Conclusions}

Blends of thermoplastic starch (TPS) and zein were obtained by melt processing of cornstarch and zein, both plasticized with glycerol. DSC and X ray diffraction showed that starch crystallizes in a B-type structure and as $\mathrm{V}$ complexes. The presence of zein seems to have no influence in the type or amount of crystalline structure of starch. Zein reduces the water absorption of the blends and decreases their

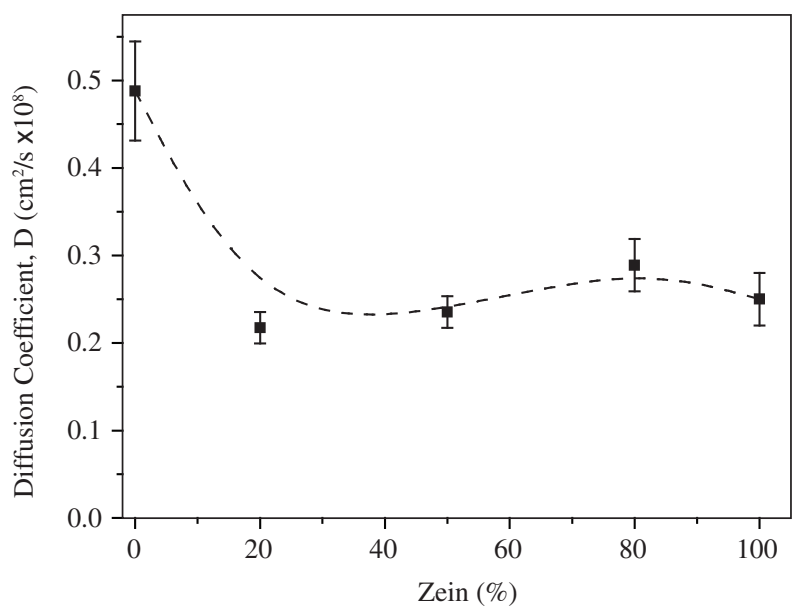

Figure 4. Diffusion coefficients of water vs. zein content for blends plasticized with $22 \%$ glycerol.

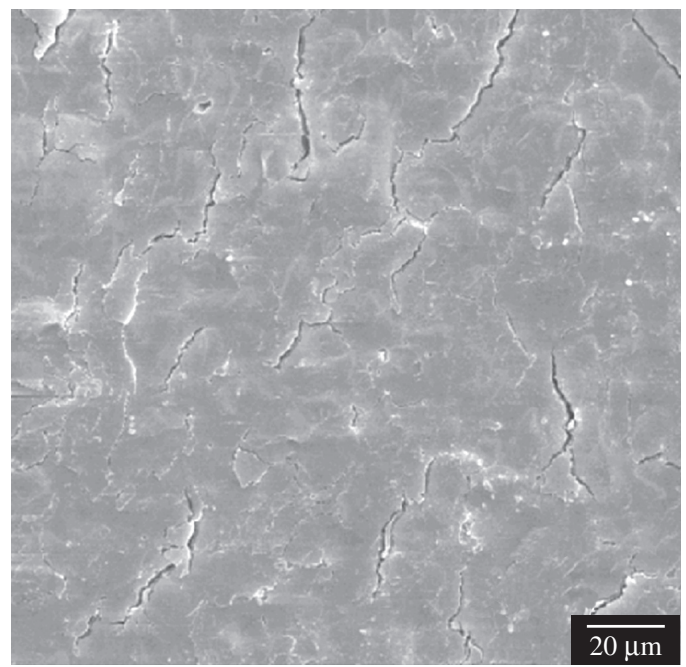

(a)

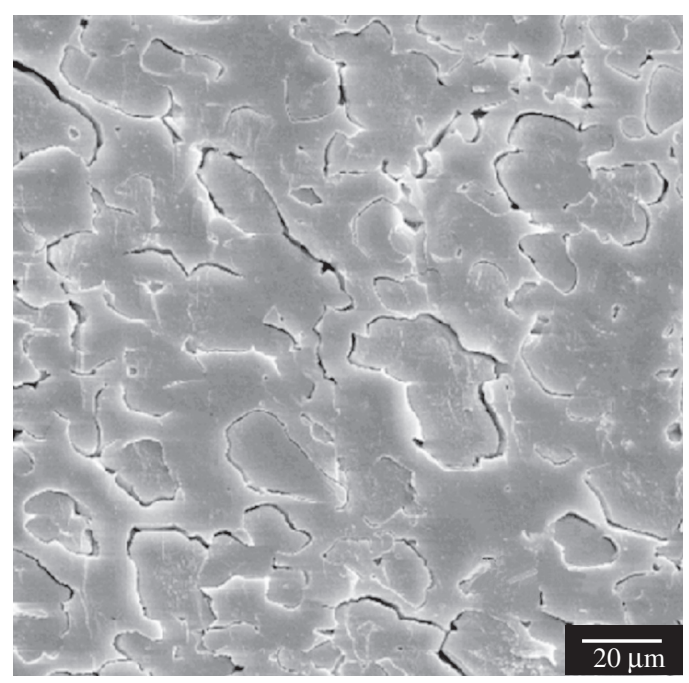

(b)

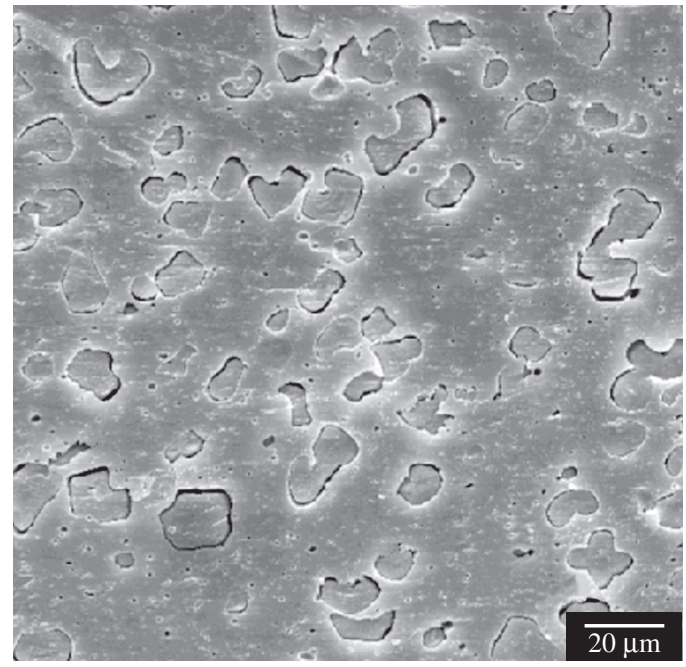

(c)

Figure 5. Scanning electron micrographs of fragile fracture surfaces obtained in liquid nitrogen of starch/zein blends plasticized with $20 \%$ glycerol: a) 80/20; b) $50 / 50$; and c) $20 / 80$. 
water diffusion coefficient, even at the lowest zein contents. Moreover, the processing of the blends is greatly facilitated by zein due to a strong reduction in their viscosity. These two favorable factors make zein a suitable and promising fully biodegradable component to be blended with starch.

\section{Acknowledgment}

The authors acknowledge the financial support provided by Fapesp and CNPq, and the supply of starch samples by Corn Products Brazil.

\section{References}

1. Briassoulis D. An overview on the mechanical behaviour of biodegradable agricultural films. Journal of Polymers and the Environment. 2004; 12(2):65-81.

2. Mohanty AK, Misra M, Drzal LT. Sustainable bio-composites from renewable resources: Opportunities and challenges in the green materials world. Journal of Polymers and the Environment. 2002; 10(1-2):19-26.

3. Gaspar M, Benko Z, Dogossy G, Reczey K, Czigany T. Reducing water absorption in compostable starch-based plastics. Polymer Degradation and Stability. 2005; 90(3):564-569.

4. van Soest JJG, Borger DB. Structure and properties of compression-molded thermoplastic starch materials from normal and high-amylose maize starches. Journal of Applied Polymer Science. 1997; 64(4):631-644.

5. Carvalho AJF, Curvelo AAS, Agnelli JAM. Thermoplastic starch-cellulosic fibers composites: preliminary results. Carbohydrate Polymers. 2001; 45(2):183-188.

6. Huang MF, Wang HY, Yu JG. Studies of biodegradable thermoplastic amylose/kaolin composites: Fabrication, characterization, and properties Polymer Composites. 2006; 27(3):309-314.

7. Corradini E, de Medeiros ES, Carvalho AJF, Curvelo AAS, Mattoso LHC. Mechanical and morphological characterization of starch/zein blends plasticized with glycerol. Journal of Applied Polymer Science. 2006; 101(6):4133-4139.

8. Bastioli C. Properties and applications of Mater-Bi starch-based materials. Polymer Degradation and Stability. 1998; 59(1-3):263-272.

9. Lawton JW. Zein: A history of processing and use. Cereal Chemistry. 2002; 79(1):1-18.

10. Hulleman SHD, Kalisvaart MG, Janssen F HP, Feil HE, Vliegenthart JFG. Origins of B-type crystallinity in glycerol-plasticised, compression-moulded potato starches. Carbohydrate Polymers. 1999; 39(4):351-360.

11. American Societyfor Testing and Materials. ASTM E104. Standart Pratice for Maintaining Constant Relative Humidity by Means of Aqueous Solutions; 1985.

12. Schramm G, editor. An approach for Rheology and Rheometry. Karlsrule: Gebruder Haake Gmbh; 1994.

13. Chedid LL, Kokini JL. Influence of protein addition on rheological properties of amylose-based and amylopectin-based starches in excess water. Cereal Chemistry. 1992; 69(5):551-555.

14. Colonna P, Buleon A, Mercier C. In Galliard T, editor. Starch: Properties and Potentials; Chichester: John Wiley; 1987. p. 79-114.

15. van Soest, JJG, Esser PJ. Influence of amylose-amylopectin ratio on properties of extruded starch plastic sheets. Journal of Macromolecular Science-Pure and Applied Chemistry. 1997; 34(9):1665-1689.

16. Bastioli C. Properties and applications of Mater-Bi starch-based materials. Polymer Degradation and Stability. 1998; 59(1-3):263-272.

17. van Soest, JJG, Borger DB. Structure and properties of compression-molded thermoplastic starch materials from normal and high-amylose maize starches. Journal of Applied Polymer Science. 1997; 64(4):631-644.

18. Angles NM, Dufresne A. Plasticized starch/tunicin whiskers nanocomposites. 1. Structural analysis. Macromolecules, 2000; 33(22):8344-8353.

19. Crank J, editor. The Mathematics of Diffusion. 2. ed. Oxford: Clarendon Press; 1975. 
